\title{
Introducción y presentación La comunidad: haciendo visible lo invisible
}

\author{
José Pérez Adán
}

Arbor CLXV, 652 (Abril 2000), 565-587 pp.

El debate político-práctico contemporáneo ha concedido protagonismo estelar al comunitarismo. No es de extrañar que desde la Tercera Vía a la Socioeconomía y desde la Ciencia Política a la Economía pasando por la Moral, la Educación, el Derecho o la Filosofía, la cuestión sobre el comunitarismo esté presente en primer plano en todas las disquisiciones modernas. Y ello tanto en el debate ideológico como en la aplicación práctica para el diseño de políticas sociales, códigos éticos y programas políticos.

Este discusión, si bien nos viene, como casi todo a lo que se da importancia en este país, de allende los mares, tiene hondas raigambres hispánicas. Hay que hacer notar de entrada que al investigador sobre el paradigma que comentamos le impactan dos fuentes documentales y bibliográficas de enorme consistencia y repercusión histórica y que tienen una indudable raíz autóctona. Nos referimos a los intentos de elaboración teórica y a las prácticas alternativas de formas de relación social que han sido propuestas desde el cristianismo y desde el anarquismo.

Por lo que se refiere al anarquismo, en el que hemos trabajado exhaustivamente (Pérez Adán, 1992), tenemos aún hoy en día una viva y rica actividad intelectual, gran parte de la misma localizada en la diáspora hispanoamericana. Las actividades del Centro de Estudios Comunitarios de Mérida en Venezuela (entre cuya producción editorial destacan los cuatro volúmenes de «Comunitarismo» aparecidos en 1984), o del INAUCO (Instituto Intercultural para la Autogestión y Acción Comunal) fundado en Valencia en 1978, amén del redescubrimiento paulatino por parte de los investigadores del carácter «postmoderno» de los entresijos ideológicos del incipiente espíritu comunitario del anarquismo español 
clásico, hacen que en la tradición cultural que se escribe en castellano la obra de los modernos comunitaristas haya de estudiarse también en base al contraste con la producción local, buscando similitudes y diferencias. En cualquier caso, los nombres de Victor García, Abraham Guillén, Ángel Capiletti, o la misma producción enciclopédica de Carlos Díaz en su esfuerzo por recuperar y proponer un verdadero personalismo comunitario, han de ser tomados en consideración por el investigador.

Por otro lado, desde el cristianismo, las diversas propuestas de implementación de la Doctrina Social Católica, que desde las Reducciones Jesuíticas y el Derecho de Gentes de la Escuela de Salamanca pasa como a escondidas por los libros de Teoría Política (los olvidos de algunos historiadores del llamado socialismo utópico para con estas producciones son llamativos), también cobra relieve cuando tratamos de explicar el comunitarismo en lengua castellana. De nuevo aquí hemos de hacer un estudio de contrastes donde, ciertamente, habremos de mencionar desde las prácticas de comunidades de bienes hoy vigentes en ciertos grupos de cristianos comprometidos, hasta las peculiaridades de los inicios de la cooperativa más emblemática a nivel mundial (Mondragón). En la misma línea, no hemos de pasar por alto que la literatura explicativa de la visión social («la sociedad nueva») que propugnan los escritos de Juan Pablo II, cuando utiliza la lengua castellana tiene carácter mayoritariamente comunitario, como nosotros mismos hemos tratado de demostrar (Pérez Adán; 1994), mientras que cuando utiliza la lengua inglesa, como en el caso de Michael Novak y muchos otros, no.

Quizá este discurso da razón de la imposibilidad cultural de traducir el debate entre comunitaristas y liberales que se viene desarrollando desde hace años al otro lado del Atlántico a la jerga castellana actual sin antes hacer referencia a las constantes y variables de la propia cultura, reto al que intentamos dar cuenta en este monográfico. Esos debates y argumentos deben de ser conocidos y explicados, pero difícilmente podríamos traducir su mensaje al castellano haciendo tabula rasa de todo lo que conforma un patrimonio cultural rico en tradiciones, fiestas y costumbres centenarias de acentuado matiz comunitario. Si acaso reseñáramos un asunto concreto, digamos que la cultura católica, a diferencia del ethos protestante, es acendrada y certeramente comunitaria. No queremos enmendar la plana al maestro Weber pero si hay un factor diferencial en la ética protestante con respecto a la católica éste es el individualismo antes que ningún otro. En efecto, la teoría de la justificación, piedra angular de la Reforma, es intrínsecamente aislante en contraste con la justificación tridentina que tiene un carácter vinculante más acusado. 
El comunitarismo es un asunto propio de muchas disciplinas y así lo intentamos reflejar en estos trabajos. No obstante es la sociología y sobre todo la obra de uno de los más importantes pensadores contemporáneos, el norteamericano de origen judío-alemán Amitai Etzioni, la que pone sobre el horizonte de crisis cultural con que nace el tercer milenio la propuesta de efectivó cambio paradigmático con que se presenta el comunitarismo en sociedad. La sociología trae a este debate una indudable lección clarificadora en la medida en que la metodología sociológica se basa en la baremación empírica y en el análisis cuantitativo como elemento de indudable utilidad.

Es en este contexto en el que tenemos que romper una lanza dentro del análisis de datos sociales a favor de la sociometría. Desgraciadamente las preferencias econométricas y los visos de legitimación exclusiva que la ciencia económica hace para. las mediciones cuantitivistas y monetarizables de manera directa y pronta, ha distorsionado gravemente la manera en la que recabamos información de colectivos humanos más o menos numerosos. La consecuencia más dolorosa de esta equivocación ha sido la creencia asumida de que la felicidad, que es difícilmente cuantificable, no se puede medir y, mucho menos, comparar.

Esto solo es cierto para los sujetos individuales pero no para los colectivos, objeto de análisis del comunitarismo. Si contásemos con instrumentos sociométricos lo suficientemente elaborados, podríamos medir y comparar los niveles de salud social de distintos colectivos humanos y a eso es a lo que nos referimos cuando decimos que la felicidad (colectiva) se puede medir. En entornos sociales definidos la virtud es discernible y medible, cosa, por otro lado imposible, cuando tomamos como referencia exclusiva al sujeto individual. Pero aún cuando esto fuese posible, no tendríamos tampoco puntos de referencia lo suficientemente fiables para medir con ello la felicidad colectiva, porque de la misma forma que la salud social no se obtiene midiendo la salud física del colectivo que tomamos como referencia, la virtud colectiva no es la suma de las virtudes (excelencias) individuales. Cuando hablamos de felicidad, de virtud, o de salud sociales, nos referimos al marco estructural, marco en el que la sociometría puede medir desde niveles de participación y equidad generacional, hasta el rango de implementación y alcance del espíritu de servicio, la tolerancia, la solidaridad o el respeto, bien sean estos factores definidos estatutaria y normativamente por la via legal o por la costumbre moral. A nuestro juicio, el desarrollo metodológico de la sociometría es indispensable para el estudio del comunitarismo y el análisis de viabilidad de sus propuestas. Ello, como puede entenderse fácilmente, ha de pasar por afianzar los instrumentos de medición y recogida de datos fácticos, rechazando asimismo la tentación de medir situaciones estructura- 
les recabando opiniones individuales (sobre todo esto hemos elaborado en detalle en nuestro La Salud Social publicado en 1999).

$\mathrm{Al}$ comunitarismo se le pueden buscar muchos padrinazgos ideológicos. Corrientes de opinión tan originales como el distributismo inglés de Hillary Belloc y G. K. Chesterton, que después influyó en el anarcorruralismo norteamericano de Peter Maurin y Dorothy Day, y que apostaba por la copropiedad frente a la cogestion recordando a todo un mundo hipnotizado con la marcha a la ciudad que en el campo no hay desempleo, o las mismas posturas del tradicionalismo francés y de Joseph de Maistre que decía que no había individuos sin entorno («yo he conocido a franceses, italianos y rusos, pero nunca me he encontrado eso que se llama hombre a secas»), se han relacionado de alguna manera u otra con los orígenes del comunitarismo. También lo han sido los kibutzim israelíes y las empresas cooperativas de las que nos ocuparemos en este proyecto. El mismo Etzioni, que, recalcamos, es la figura más señera de entre todos los que se han dedicado a glosar la opción comunitarista, señala a pensadores tan diversos como Martin Buber, Emile Durkheim, y Ferdinand Tönnies como precursores del moderno comunitarismo.

Que el comunitarismo esté de moda puede incluso explicarse como una de las lógicas connotaciones de contrapeso de una cultura obsesionada con la imagen, con lo plástico, con la forma, y con los perfiles y contornos. En este sentido se trataría de hacer visible lo invisible pues la comunidad a diferencia de los individuos y ciertas agrupaciones de individuos no se puede fotografiar, filmar, aclamar, silbar, dibujar, vestir, ni reconocerla en el espejo. Y sin embargo existe. Notamos su falta en el auge de la criminalidad cuando añoramos la necesidad de desaprobación colectiva y de rechazo más allá de la ley penal para con ciertos comportamientos antisociales. Son los defectos de socialización que Etzioni ha glosado comentando el dicho de «hace falta más pueblo y no más policía para erradicar crímenes e insolidaridad». La comunidad no se ve y no obstante sin ella no sabríamos nada, ni siquiera caminar erguidos. La comunidad aparece visible solo cuando miramos más allá de los fenómenos y de las formas y cuando aprendemos a dialogar y a relacionarnos diacrónicamente con quienes nos han precedido o nos van a suceder, y sincrónicamente con quienes solo por apreciaciones indirectas podemos reconocer como coetáneos. De modo análogo, cuando decimos que la sociedad es encuentro (Buber), o cuando afirmamos que la vida son relaciones (Donati), o defendemos que la felicidad es una puerta que se abre hacia fuera (Kierkegard), también estamos haciendo visibles verdades invisibles.

Es en este contexto en el que podemos considerar a la comunidad como un sujeto colectivo en el que se practica la civilidad y del que se 
sorprendido a todos por su rápida consolidación en el mundo universitario, y que después reproduce el comunitarismo. Propiamente hablando la socioeconomía nace en 1988 en Harvard de la mano de Etzioni, desde entonces eterno candidato al nóbel. Hoy en día la Asociación Mundial de Socioeconomía es de las más numerosas y prestigiosas del mundo en su género y en España funciona un capítulo desde 1990. Tras la fundación de la Asociación Mundial de Socioeconomía, Etzioni funda la Red Comunitaria en 1989.

Para el comunitarismo tan lejano está el presupuesto neoclásico de la naturaleza armónica y espontánea del bien social extenso que se deriva del intercambio libre (la mano invisible), como la premisa del consenso óptimo al que conduce la deliberación racional entre sujetos con diversos códigos morales para la acción colectiva. Los comunitaristas no están por tanto ni con el neoliberalismo económico ni con el liberalismo clásico. Por un lado se afirma que los óptimos sociales no son consecuencia del procedimiento (el consenso) sino que son reconocibles en sus resultados, como nosotros demostramos en La Salud Social (1999). Por otro, se defiende que la deliberación y el intercambio no solo deben contemplar a los actores sociales que son capaces de presentarse en el ágora pública sino también aquellos que no son fácilmente reconocibles ni por su voz ni por su forma, entre otras cosas porque pueden ser de otro tiempo pasado o futuro o porque no sean capaces de hablar o porque se les ignore. Se entiende con esto que para el comunitarismo tengan peso específico propio las tradiciones, la historia, la cultura, la identidad, la religión, en definitiva todo lo que se considera depositario de valor colectivo agregable al monto de calidad moral de toda la sociedad en su conjunto para servicio de las diversas comunidades y de sus miembros.

Quizá el punto de arranque del comunitarismo moderno haya sido la problemática medioambiental y en concreto la necesidad de considerar los aspectos de diacronía social para entender sobre la bondad de la preservación del entorno natural. La diacronía social es para la sociedad y cultura contemporáneas una de esas facetas invisibles que conviene mostrar y conocer. Y es que es el individualismo de nuestra cultura lo que en mayor medida ha contribuido a que sea cada vez más difícil pensar en la sociedad como un colectivo vivo a través del tiempo y más allá de los individuos y de sus acciones. Sin diacronía no hay responsabilidad para con la siguiente generación y por tanto no necesariamente es mejor la preservación del medio ambiente que su acabamiento. Sin diacronía la única salida viable que le queda a la economía neoliberal de salvar el medio es tacarln caro, hecho, por otra parte imposible, si se prescinde de preguntar a sus benefactores (también los potenciales) cuánto vale. 
puede predicar la virtud. Se trata de un objeto de estudio muy propio de la sociología. En cierto sentido, estamos retomando a Durkheim y su estudio sobre el suicidio, porque ¿no nos dice algo sobre la salud social de un colectivo el índice de suicidios? ¿no tendremos que definir y diferenciar claramente las patologías sociales en sujetos grupales para hablar de virtud, felicidad o salud, en el sentido al que aquí nos referimos? No es de extrañar que Etzioni explícitamente se refiera al comunitarismo como una intento de plasmar en la esfera pública la comprensión de la vida y la acción social que proporciona la sociología de la virtud.

El paradigma comunitarista, que al hablar de comunidad se refiere a un sujeto colectivo para el que reclama cierta soberanía y del que propugna la independencia conceptual frente a esos dos grandes monopolizadores en exclusiva de la soberanía tal y como la entiende la modernidad que son el individuo y el estado, no define la comunidad de manera unívoca y, ciertamente, no con terminología espacial (las fronteras sociales no se pueden ver en los mapas). La comunidad es un entorno humano donde la virtud tiene un atributo social y donde, por tanto, existe una conciencia moral compartida. Pueden, y de hecho hay, existir comunidades residenciales, pero también étnicas, religiosas o laborales. Por eso, a la hora de adscribir nuestro objeto de estudio aquí, no nos sirve la distinción entre sociedad política y sociedad civil: más bien estamos hablando de un entorno cívico (político o civil) en el sentido de un ámbito de civilidad.

Si algo denuncia el comunitarismo como pernicioso y antisocial es el individualismo. Ello explica que la socioeconomía, que se presenta como alternativa al reduccionismo individualista neoclásico, esté íntimamente relacionada con la opción comunitarista. Sin duda alguna, la ciencia económica está sufriendo su primera gran crisis como disciplina académica por haber excluido a los sujetos colectivos como sujetos de racionalidad. Por ello, como ha defendido Etzioni fundador a su vez de la socioeconomía, el mismo asentamiento como ciencia de la economía moderna está en entredicho: la variedad de recetas «científicas» y el virulento enfrentamiento entre los que la practican le quita crédito ante los que sufren su ineficacia para catalogar y resolver los problemas actuales. No está del todo desacertado Buchanan al calificar de analfabetos a tantos economistas que, cegados por la aparente exactitud de sus modelos y la sofisticación de sus diagnósticos, han perdido la capacidad de entender que el mercado tiene un entorno social propio y funciona inmerso en una realidad concreta. Efectivamente, a la ciencia económica actual le sobra tecnicismo y le falta realismo. Esto es, entender qué caracteriza a una sociedad cumo humana. Este reto es el que toma inicialmente la sociveconomía, que ha 
Se entiende que para el comunitarismo no haya relatividad social. No todas las sociedades son igual de buenas. Unas valoran más lo que más valor tiene que otras ( por ejemplo, en unas el medio es un bien a preservar y en otras un producto a explotar). Por ello los óptimos sociales existen en la medida en que podemos discernir entornos con mejor salud social que otros. Tenemos aquí un concepto cualitativo de lo social.

Para el comunitarismo lo social es, pues, de alguna manera normativo. En este sentido se está más cerca de Durkheim que de Tönnies. La comunidad, que dicho sea de paso debe de entenderse siempre como plural (todos pertenecemos a varias comunidades al tiempo), no es un mero «lugar» donde se celebran las relaciones afectivas, es también y sobre todo un compartir valores que se intentan reforzar, preservar y expandir porque se consideran óptimos. En este sentido la comunidad son más los valores que el espacio.

Ahora bien, no debe entenderse esta apuesta por los valores compartidos como una defensa del estado. Más bien al contrario. El mensaje comunitario de más sociedad y menos estado nos señala al gran ocultador. Es el estado el que ha escondido la sociedad a nuestros ojos y cuando afirmamos la conveniencia de hacer visible lo invisible estamos también subrayando la necesidad social de revitalizar la colectividad frente al estado. O sea, buscar las señas de identidad colectivas es aspectos sociales sustantivos (un contenido en valores) y no en uniformes, banderas, himnos y deporte (un envoltorio en colores vivos).

Un supuesto básico que está sosteniendo toda la argumentación del comunitarismo es que, aun estando de acuerdo con la apuesta en los valores y a fuer de seguir siendo políticamente incorrectos (nos place este antiestatismo) para defender una posición que consideramos socialmente correcta, hemos de apuntalar la fórmula que nos permite llegar a la igualdad de las personas a través de la jerarquía de los valores (léase también derechos y comunidades). Nada mejor que una jerarquía para defender otra igualdad. Nos explicamos.

Para el comunitarismo llegar a señales o síntomas de excelencia social en el reconocimiento de urgencias y prioridades valorativas es sinónimo de apostar por la igualdad de las personas. Así, por ejemplo, el reconocimiento de la superioridad del derecho a la vida sobre el derecho a la propiedad es la garantía básica de un ordenamiento jurídico justo en lo que atañe a la equidad entre las personas. De igual modo la excelencia del valor protección de la naturaleza sobre el valor libertad de elección de actividad deportiva concreta, o la mayor importancia de la comunidad Cruz Roja sobre la comunidad de Tiro con Arco. La defensa de la familia que hace el comunitarismo se basa precisamente en esta línea ar- 
gumentativa. En un artículo aparecido en el The Weekly Standard el 20 de Noviembre de 1995, titulado «Which values matter most?» Etzioni fue inequívoco al respecto: «sin un acuerdo básico sobre lo que constituye y conforma una familia, no se pueden argumentar ni sólidas políticas ni una básica mejora social».

La familia es la comunidad más básica y mucho se tiene que argumentar sobre la necesidad de devolverle cotas de soberanía ahora detentadas por el estado. He aquí también una de las facetas invisibles que hay que desvelar. La mayoría de la población en los países más desarrollados no duda en reclamar menos estado y menos gobierno pero al mismo tiempo esta reclama va acompañada de deseos explícitos de beneficiarse de una mejora sustancial en los servicios públicos. La canturrela suele formularse así: menos impuestos y más servicios, menos trabajo y más salario, menos restricciones al consumo y más naturaleza, menos milicia y más seguridad, gasolina más barata y aire puro. Al final la componenda es cambiar el gobierno que no convence al electorado para que modere sus demandas. Se trata de una componenda mal planteada. La manera más certera de dar cumplida cuenta de unas legítimas reclamas que no son ni mucho menos irreconciliables, es ofertar los servicios cada vez de manera más organizada no desde la burocracia estatal sino desde la participación comunitaria. Para ello es fundamental reconocer a la comunidad protagonismo público, empezando por lo que nosotros hemos llamado el reconocimiento de la soberanía familiar en áreas, como la educación y la representación, donde esta soberanía puede ser ejercida con reconocimiento y beneficio social.

Ciertamente, en vista de lo dicho hay que subrayar que el comunitarismo no participa de ese pesimismo sobre la naturaleza humana que caracteriza tanto al conservadurismo (dejados a su libertad los hombres se aniquilarían entre sí) como al liberalismo neoclásico (la racionalidad humana supone la maximización del beneficio). La misma historia de la familia muestra (en verdad que para darse cuenta de ello hay que reconocer a la comunidad familiar como sujeto) que la comunicación de valores es algo connatural a la especie humana, al menos hasta ahora.

Bien es verdad que la familia solo es una de entre las varias comunidades de las que un individuo puede ser parte. La ciencia social muestra claramente que el deterioro de la vida familiar aumenta la criminalidad. Pero también hay evidencia de que familias que podíamos calificar de óptimas, incluso cuando son apoyadas por una organización formal de educación, una escuela, seria y excelente, no necesariamente sitúan a sus miembros en un entorno saludable socialmente hablando. Señal evidente de que el resto de comunidades, desde el ambiente de barrio a los gru- 
pos formales de solidaridad o a la comunidad ciudadana en su conjunto, necesitan también un reconocimiento social básico que les facilite reconocerse como sujeto colectivo y les permita baremar contextualmente sus propias excelencias y deficiencias de manera que sean discernibles desde dentro y desde fuera.

No existe aquí una radical incomprensión entre derecho y deber, entre libertad y responsabilidad, entre individuo y colectividad. La imagen que más propiamente representa la fundamentación del mensaje social comunitarista es la de la bicicleta. Hemos de resaltar, de una parte, el equilibrio dinámico que supone un viaje en bici frente al estático de las cuatro ruedas. Cada tiempo y cada trazado tiene sus propias necesidades de contrapesar la inercia poniendo la fuerza en uno o en otro lado. Unas veces será en el lado colectivo y en los deberes sociales y otras en el individuo y sus derechos; el equilibrio, en definitiva, abraza los dos lados. La sociedad y el individuo son, de otra parte, las dos ruedas del vehículo. En el comunitarismo hay tendencias y hay comunitaristas que podíamos llamar de derecha que ponen un mayor énfasis en la defensa de las libertades individuales, su radicalización trasformaría la bicicleta en un monociclo libertario en el sentido norteamericano de la expresión. Hay también comunitaristas de izquierda que acentúan los vínculos sobre las peculiaridades y cuya radicalización transformaría la bicicleta en un monociclo socialestatista. En cualquier caso los monociclos son la antítesis del comunitarismo. Los comunitaristas bien poniendo delante una rueda u otra, más grande o más pequeña, viajan en bicicleta haciendo equibrios.

El dilema entre liberalismo y socialismo no tiene al comunitarismo como su diagonal. El comunitarismo no es aquí un punto medio y por tanto huelga hablar de Tercera Vía o de Centro Reformista como opciones políticas herederas del comunitarismo. Hay un equilibrio entre individuo y sociedad en el mensaje comunitarista pero los comunitaristas son al mismo tiempo liberales y socialistas. Creer como creen los liberales que la gente escogería no violar los derechos de otros en la medida en que ello les beneficie es tremendamente ingenuo, y pensar, como piensan los socialistas, que el estado puede hacerse presente cada vez que la libre iniciativa no baste para mantener el equilibrio y el orden social y solo en esas ocasiones, también. Los comunitaristas son liberales cuando defienden el estado mínimo y son socialistas cuando apoyan la expresión y sanción colectiva de la virtud. Pero donde radicalmente difieren de unos y de otros es en considerar la comunidad, ni al estado ni al individuo, como la piedra basal del orden social.

La misma investigación social comparada nos da razones de esta consideración. En un extremo tenemos ordenamientos donde hay máxima 
injerencia estatal en la vida y en el comportamiento relacional individual y mínima injerencia comunitaria (masas anónimas), en otro extremo tenemos asentamientos seculares o religiosos con mínima injerencia estatal y máxima injerencia comunitaria (comunas, villas y pueblos). El análisis efectuado por el examen permite afirmar que la comunidad es más eficiente que su ausencia o que el estado conformando orden social y garantizando el mejoramiento de la salud social de los colectivos propuestos. El estudio lo llevó a cabo la revista Science en el número monográfico del 15 de Agosto de 1997 para concluir que la delincuencia, los comportamientos de riesgo, y los actos antisociales en general, son más fáciles de prevenir y reducir donde la comunidad censura esos actos de manera explícita y clara. El estudio, que también incluyó el examen de colectivos sin agrupación espacial, apuntaló la gran importancia que tienen las familias, amistades, asociaciones, agrupaciones y organizaciones varias, así como mayormente la opinión pública, en procurar estabilidad social frente a la poca relevancia comparativa que tiene la burocracia estatal.

Bien, parece que ya entendemos por dónde va el comunitarismo, pero ¿cómo calibramos su importancia para el mundo contemporáneo? ¿están los comunitaristas en lo cierto cuando claman por un cambio de paradigma convivencial?

Sírvanos para glosar este punto la propuesta que Etzioni presenta en su obra más decidídamente comunitarista, LA NUEVA REGLA DE ORO, y que supone una alternativa al viejo «haz a los demás lo que te gustaría que hiciesen contigo", y que quedaría en los siguientes términos: «respeta y acata el orden moral de tu entorno social como te gustaría que este respetase tu autonomía». La razón de la nueva formulación etziniana deriva de una apreciada rotura del equilibrio entre orden y autonomía que se vislumbra en la mayoría de las sociedades modernas. Para los comunitaristas ello es el resultado de la acumulación de los cambios sociales que se han condensado en los últimos 30 años y de cuya magnitud no tenemos referencia parecida en toda la historia.

La nueva regla de oro habrá de aplicarse primando el contenido de una de las partes de la balanza (la autonomía) unas veces y en unos lugares, y de la otra parte (el orden) otras veces y en otros lugares. Lo importante es el equilibrio que independientemente del contexto histórico y sociopolítico, tendrá que ser mantenido ejerciendo acciones diversas, en uno u otro sentido, según sea la naturaleza de los desequilibrios detectados.

Si nos atenemos a la comprensión de los procesos de cambio social en las sociedades industriales avanzadas del mundo occidental, el comuni- 
tarismo denuncia como disfuncional la generalización de la cultura atomizante y disgregadora que propugnada por el individualismo ha tenido en las prácticas consumistas generadas por el materialismo capitalista su principal causa cercana. En este sentido Etzioni se situa en la tradición clásica que en sociología marcan Durkheim, Park, Nisbet, Tönnies y Parsons, en filosofía Dewey, Mead y Buber, y en la acción sociopolítica inniciativas como New Harmony (J. Warren) y los Kibbutzim. Entre los más señeros continuadores de esta tradición Etzioni reconoce hoy en día a Bellah, Selznick y Daniel A. Bell.

El desequilibrio entre autonomía y orden moral que denuncia el comunitarismo no debe de entenderse como una reedición de la vieja confrontación entre libertad y orden. No estamos en la esfera política sino en la social estrictamente hablando, hasta el punto que lo que se busca es un equilibrio que asegure ambas partes de la balanza, la autonomía y el orden, basado éste en la sanción moral colectiva y no en la sanción legal o penal. La nueva regla de oro no es un nuevo dictum sobre el que edificar las relaciones interpersonales: se trata de un modus operandi para la acción intrasocial. Si nos imaginásemos un debate a dos bandas entre iguales, los sujetos que dialogarían sobre la nueva regla no serían dos sujetos individuales o cualquier par de individuos o todos los individuos a pares, sino el individuo y la colectividad de la que se siente parte o cada individuo y la colectividad de la que se siente parte. La víctima del desequilibrio que denuncia el comunitarismo en el mundo capitalista occidental es la colectividad: mucho menos poderosa (soberana) que el individuo con el que pacta.

De lo que se trata es de huir de los excesos. La pregunta que salta inmediatamente como un dardo arrojadizo es: ¿acaso se piensa que un $e x$ ceso de autonomía puede darse o ser disfuncianal? Pues sí, esta es, además, la gran falacia del liberalismo: los «excesos» de libertad (se entiende: no estructural) incapacitan a la libertad misma. Pasado un máximo socialmente sostenible, cuantas más libertades, menos libertad.

Esto se entiende cuando nos damos cuenta que el ejercicio de la libertad tiene un ámbito propio que es la sociedad. La libertad antisocial es una disfunción catalogada muchas veces como desviación. Por ello cuando aumenta la oferta de libertades sin aumentar al mismo tiempo la oferta de seguridades colectivas: cuando crece la autonomía y disminuye la salud social, se produce una situación de déficit de orden moral que hay que tratar de paliar. La imagen de un individuo que presumiese ante otro de ser más libre que aquel por disponer el primero de $30 \mathrm{ca}-$ nales de televisión donde elegir mientras que el segundo solo dispone de 20 , nos parecería ciertamente ridícula. La libertad no aumenta de forma 
necesaria con la maximización de la capacidad de elección. Poner a los derechos individuales a competir con los deberes sociales no tiene sentido. Como en el dilema del prisionero a la postre, ambos, sociedad e individuo salen perdiendo. La autonomía está mejor servida cuando procura el amparo y tutela de la salud social y el orden moral sobre la que se asienta.

Aquí el liberalismo ha sido conscientemente engañoso. Incluso desde sus mismas premisas, la maximización ilimitada de la capacidad de elección individual es difícilmente sostenible de forma coherente. La promesa del incremento de la autonomía que ha sido su estandarte durante muchos años ha rendido beneficios individuales concretos y a corto plazo, pero ha dejado también muchas facturas impagadas: la medioambiental y el incremento de la desigualdad planetaria son quizá las más llamativas. Pero además, y sobre todo, el liberalismo no ha conseguido proponer una idea de bienestar mínimamente consensuada. Y es que, el exceso de autonomía puede ser «excesivo» en más de un sentido. Por un lado, puede devenir en situaciones de irracionalidad como cuando un incremento en el número de opciones hace inviable la elección si a ésta se le supone una previa información pormenorizada difícilmente abarcable a partir de un cierto grado, o manifiestamente costosa. Por otro, puede dificultar el autocontrol que es un forma de autonomía, como cuando la facilidad del acceso a armas o drogas dificultan la convivencia pacífica. Aún en un tercer sentido, descartar unas posiblilidades de opción que pueden considerarse como superfluas a priori para centrar la elección en otras, puede implicar unas responsabilidades por las que no se ha optado manifiestamente, o suponer compromisos no suficientemente informados, o crear potenciales espacios de conflicto en el entorno de relaciones humanas próximo e inmediato.

La irreflexividad, la misma imposibilidad de adoptar decisiones colectivas, y, sobre todo, la dificultad para ver en el conflicto entre autonomías un elemento de dinamización social, hacen que la cultura de la maximización de la capacidad de elección rompa poco a poco el tejido social que cobija las libertades. Este diagnóstico comunitarista puede perfectamente invertirse cuando consideramos el contexto de una sociedad sobresocializada compulsivamente, como puede ser un estado totalitario. Ahí el equilibrio habría que buscarlo encontrando formas de primar el desarrollo de la capacidad de elección. Queda, no obstante, patente que en Etzioni, su intento de hacer una sociología de la virtud en el mundo occidental, resulta en una llamada urgente por cargar peso en el plato del orden moral. Aunque, como veremos después, esto haya de llevarse a cabo desde iniciativas colectivas no gubernamentales. 
El comunitarismo se ha mostrado siempre cuidadoso de incluir entre sus listas de apoyo a políticos profesionales procedentes de los dos lados del arco parlamentario: en los EE. UU., Jack Kemp y Al Gore, y en Europa, Tony Blair y Helmut Kohl. Se trata de un difícil ejercicio de moderación y de cuidado de la imagen que es, visto desde dentro, hasta cierto punto engañoso. Al comunitarismo no se le puede «situar» parlamentariamente hablando, porque la terminología derecha-centro-izquierda no le sirve. De hecho, esta tipología es denunciada como irrelevante desde el punto de vista de su capacidad de conformar identidades colectivas que puedan eficazmente enfrentarse con los grandes problemas que tiene planteados la sociedad contemporánea (la desigualdad y el medio ambiente, ya mencionados, y las distintas patologías sociales).

Donde más manifiestamente se ha visto la inadecuación de la conformación ideológica en base al lugar del parlamento donde unas personas asientan sus reales, es en las contradicciones internas en las que los miembros de las distintas formaciones políticas caen a la hora de definirse en temas que afectan a lo que los comunitaristas llaman la voz moral de la sociedad. El caso español es particularmente paradigmático. La razón ideológica por la que la izquierda ha de apostar sistemáticamente por la destrucción de la familia, o las derechas, que muchas veces se llaman conservadoras, por la reducción de la cobertura de protección de las clases pasivas o la "asimilación» cultural en política exterior, escapa todo intento de encontrar una postura de coherencia interna, como creo que explicamos en su día en una pieza para la difusión general (cfr. «El aborto es de derechas» Levante, 15,XII,1992). Para el comunitarismo, la perpetuación del estancamiento de la diferencia entre izquierda-derecha impide que una diferenciación ideológica que se ha mostrado saludable para solucionar los conflictos generados por la revolución industrial, se adecúe a prestar un servicio similar para solucionar los conflictos de convivencia que se presentan en este fin de milenio. Para los comunitaristas, la bipolarización izquierda-derecha, ha de ser superada para enfocar la atención pública en los problemas sociales genuinamente relevantes. Ahí, la distinción que cabe hacer es entre individualistas y societarios.

La diferenciación que acabamos de apuntar es genuinamente paradigmática. Aun cuando estemos refiriéndonos a la dicotomía social entre autonomía y orden moral, y ésta se plantee de distinta manera según el espacio, el tiempo, el contexto y la cultura, los desequilibrios que se intentan subsanar son mejor entendidos cuando dividimos el campo conceptual entre individualistas y societarios independientemente del contexto político y geográfico al que nos refiramos. Por ello esta nueva 
polarización puede calificarse de genérica aunque al separar los campos hayamos de hacer referencia a las circunstancias locales. Esta es una tarea que han de llevar a cabo en cada lugar los que en ese contexto intenten proponer soluciones comunitaristas a los problemas de desequilibrio detectados entre autonomía y orden.

La distinción y el despeje del campo que hace Etzioni para el caso estadounidense nos puede servir de ejemplo. Pensando que una sociedad equilibrada no persigue ni la maximización de la autonomía individual ni la del orden moral, Etzioni situaría al comunitarismo norteamericano entre unos maximizadores de la autonomía (individualistas) que son legión, y unos maximizadores del orden moral (societarios) que hoy en día están escasamente representados en los foros de debate público. Entre los primeros situaríamos a representantes tanto de la derecha como de la izquierda contando a: libertarios (en el sentido americano del término: los defensores del estado mínimo), liberales, conservadores partidarios del laissez faire, neoconservadores de derecha, y a los defensores de los derechos civiles (civil libertarians) percibidos como de izquierda. Entre los segundos, los societarios, cabría situar a los conservadores partidarios del estado moral (social conservatives).

El comunitarismo se situaría a mitad de terreno entre unos y otros, enfatizando más que nunca que la comunidad no es un lugar sino un conjunto de atributos, hoy minoritariamente defendidos. Ciertamente, si vemos el elenco de los que Etzioni agrupa como individualistas, nos encontramos con gran parte de la intelectualidad norteamericana y con toda la herencia del liberalismo anglosajón. Ahí estarían: Locke, Smith, Mill y Bentham; Dworkin, Hayek, Rawls y Nozick; y también Galbraith y Berlin. Entre los societarios contaríamos a Burke, Oakeshott, Kirk y MacIntyre. Los economistas neoclásicos y la Escuala de Chicago en bloque, así como los partidarios de la Teoría de la Elección Pública en ciencia política y los partidarios de la Teoría del Intercambio en sociología, representarían mayoritariamente los intereses del individualismo.

A nosotros, que no estamos en situación ni en momento de establecer elencos españoles precisos (un cierto apercibimiento puede conseguirse consultando la página web de SASECE, el Capítulo Español de la Sociedad Mundial de Socioeconomía), sí que nos interesa en este momento remachar la idea de la refundación política implícita en esta nueva divisoria. Si marcamos el arco parlamentario por los parámetros que proporciona la distinción entre individualistas, comunitarios y societarios, quédenos claro que al nuevo paradigma comunitario pertenecerían todos lo que entendiesen la sociedad como una comunidad de comunidades basadas en la participación, el diálogo y los valores compartidos. 
Estamos ya en situación de explicar las consecuencias sociopolíticas que se derivarían de un estudio pormenorizado del estado de la virtud en una sociedad, tal y como propone que se haga ese estudio el paradigma comunitarista. Se trata de un estudio a la vez sociológico e histórico; sociológico porque tratamos de discirnir un estado de equilibrio societario entre autonomía y orden como marco operativo donde podemos vislumbrar máximos de salud social, e histórico porque tratamos de hacer balance y diagnosis de nuestra situación y desarrollo para saber cuánto hemos recorrido, y a qué velocidad y por qué caminos hemos de transitar la distancia siguiente.

Considerando que estamos refiriéndonos a un sujeto colectivo que actúa históricamente y que detenta valores compartidos, hemos de matizar la consistencia de lo que se supone aglutina y conforma ese actor social que llamamos comunidad. Nos referiremos sobre todo, a la existencia de una red de relaciones afectivas de alguna clase y a la conciencia de la pertenencia manifestada en la constatación empírica de la existencia de valores comunes asumidos tácitamente. La sociedad, como dejó claro Etzioni en su The Active Society ya en 1968, no es un mero sujeto pasivo del devenir. Los valores no se heredan: se viven o mueren. Por eso la conciencia de pertenencia supone la autonomía individual y no la anula.

$\mathrm{Al}$ estado le estamos dejando en todo este discurso un rol de subsidiaridad. Al menos en la situación que detectamos en las democracias occidentales, el papel del estado ha usurpado la discrecionalidad de las sociedades intermedias mediante la alianza monopolizadora que la modernidad concertó entre la soberanía estatal explícita en las constituciones nacionales y la soberanía individual explícita en las declaraciones de los derechos humanos. Es por esto que el comunitarismo taxatívamente argumenta que la acción social debe de ser no solo incentivada sino también canalizada (reprobada) por la sanción moral y no por la sanción legal. El intento de construir ámbitos de moralidad en base a la iniciativa legal y al código penal degenararía en totalitarismo. De lo que se trata es de dar capacidad normativa en el uso y costumbre, que no en la ley, y si acaso ésto solo secundariamente para proteger de la violencia a lo anterior, a la soberanía de las sociedades intermedias que llamamos comunidades.

Se pide una muestra de confianza en la voz moral de los colectivos humanos superior a la que se tiene en los mecanismos de coerción y en la codificación de conductas públicas por el legislador. "Puesto que la sociedad ni es ni debe de identificarse con el estado, la acción social debe de considerarse prioritaria sobre la acción política» (Etzioni, 1996;141). Es en este contexto en el que podemos entender a las leyes como continua- 
ción de la moralidad por otros medios, pero en ningún caso podemos concederle a la ley la fundamentación primera o el basamento del orden.

La formulación del paradigma comunitario ha supuesto un replanteamiento del debate político en muchos países y paradigmáticamente en los EE. UU. Allí donde este replanteamiento se ha dado, la vieja dicotomía derecha-izquierda ha tenido que ser superada. Como el comunitarismo no conlleva ningún mensaje de acción violenta, esta superación ha tenido que asentarse en vehículos alternativos promotores de cambio. Es por ello que «la invitación a la acción» de la que habla Etzioni en casi todas sus obras suponga la conformación de megálogos sobre los temas de relevancia social.

El megálogo, que entendemos como un supradiálogo en foros y medios variados al que los ciudadanos tengan acceso activo o pasivo, es posible si tomamos en consideración el nivel de sofisticación a que ha llegado la intercomunicación humana. Los megálogos generan opinión colectiva y hacen visibles valores y virtudes, pudiendo hablar, como consecuencia, de la voz moral de un colectivo. Es la imagen de la sociedad en acción que tiene entidad propia y que es anterior al individuo.

Ciertamente, la visión juglaresca que el individualismo ha transmitido del mítico «contrato social» no tiene ninguna fundamentación histórica. Lo cierto es que todos nacemos en una sociedad que ya existe. Por eso las fuentes primarias de valor son culturales y no personales y esto es cada vez más cierto en la medida en que los mecanismos e instrumentos de socialización (entre los que hemos de contar hoy en día con los megálogos) han ido perfeccionándose afectando a más individuos y de manera parecida.

Una distinción cabe hacer ahora. No debemos confundir el diálogo moral con la deliberación racional. El primero, que es la parte del megálogo que aquí nos interesa, incluye elementos que el racionalismo considera «perversos» como los afectos, emociones, pasiones y gustos. Es conocida la aversión comunitarista a los criterios de racionalidad que ha defendido como exclusivos el neoclasicismo económico (Pérez Adán, Socioeconomía, 1997). Pensamos que partiendo de los criterios emanados del modus operandi de la deliberación racional, difícilmente podemos conformar comunidades plurales entre las que sea posible la diferenciación. Las sociedades intermedias no tienen una legitimación deliberativa sino moral.

Así, los megálogos, perfeccionan la sociedad en la medida en que la hacen visible a sus miembros. El comunitarismo defiende una concepción dinámica de la sociedad humana donde cabe el progreso y la decadencia. La sociometría debe de ayudarnos a detectar si vamos en un sentido o en 
otro, en la medida en que apreciemos una mejora o un empeoramiento de la salud social. Para Etzioni (1996; 179-187), hay tres factores que condicionan o aseguran unas mínimas cotas de salud social. En primer lugar, la capacidad de internalización del orden moral por parte de los individuos que se mide negativamente a través del cotejo de actitudes que puedan catalogarse como desviadas. En segundo lugar, el desarrollo y consolidación de la acción social en base al afianzamiento institucional desde la base de la familia, la escuela, la comunidad y la sociedad en su conjunto. $\mathrm{Y}$, en tercer lugar, la apreciación del equilibrio intrasocietario entre orden y autonomía.

La capacidad de autoperfeccionamiento social debe de hacernos ver que en el terreno de la civilidad la democracia no es un estado que hay que consolidar, en el sentido de perpetuar, sino un valor y, por tanto, un proceso que hay que continuar ininterrumpidamente, introduciendo variables estructurales de modo paulatino. En este sentido somos peregrinos: hacemos camino con nuestras pisadas. Por lo que afecta al continuo incremento de poder que las soberanías consolidadas se autootorgan con cada innovación tecnológica, con cada ordenamiento legal, con cada regulación y con cada monopolio fáctico, la democracia debe de entenderse como una máquina que dispensa poder, en el sentido que lo distribuye de manera continua y equitativamente. La capacidad de la comunidad para autoregularse y autoconocerse es quizá la primera condición por la que debe velar el sistema democrático.

El auge del comunitarismo, que es en definitiva una alternativa sociopolítica importante, en países donde aparentemente parecen disfrutarse altos niveles de bienestar pone en entredicho los sistemas de medición econométrica. Y es que precisamente la situación de estancamiento del proceso democrático ha supuesto una relativa disminución de los niveles de salud social que cuestionan a su vez el mantenimiento de la cultura convivencial moderna. Incluso dejando al margen esas dos grandes lacras del estancamiento democrático que son el aumento de la desigualdad y el deterioro medioambiental, en los países llamados avanzados se detecta un fuerte auge de diversas patologías sociales.

Estas patologías son detectables mediante dos niveles de análisis. El que hace la sociometría de la salud pública y el que hace la sociometría de las relaciones humanas. Si consideramos la salud pública y hacemos una distinción entre causas de muerte debidas al comportamiento y causas de muerte debidas a la inclemencia, es ilustrativo que en los países occidentales primen con mucho las primeras sobre las segundas. No es el momento de traer aquí una elaboración estadística compleja, que por otro lado publicaremos más adelante, pero las muertes por accidentes, por 
violencia, por el uso de sustancias adictivas, por estrés, por comportamientos de riesgo, superan (en España esto es así, como en casi todo Occidente) a las muertes debidas a inclemencias epidémicas y a enfermedades verificables como totalmente ajenas al comportamiento mimético informado, que son más numerosas en otros países.

$\mathrm{Si}$ ahora consideramos las relaciones humanas y tratamos de medir niveles de salud social, observaremos que el deterioro verificable contrastando indicadores de disfuncionalidad aumenta con el auge del individualismo. El caso norteamericano es el más estudiado, pero también en España podemos constatar un aumento de factores como: la monoparentalidad, la criminalidad (también la infantil), la insolidariad generacional (el impago de la deuda filial, por ejemplo), o el suicidio. Es curioso ver cómo Durkheim nos aparece ahora como un autor tremendamente actual.

En esta tesitura, reconocemos, como hace Etzioni (1996; 93), que lo importante a la hora del estudio del comportamiento humano no es la distinción entre público y privado. Si la virtud no entiende de escenarios, lo realmente interesante es distinguir entre comportamientos o actitudes socialmente saludables (independientemente del ámbito) o no. El caso es que a la postre, disfunciones, que a primera vista parecen de muy poca relevancia para la felicidad colectiva medible como salud social por considerarse como estrictamente privadas (caso del divorcio, por ejemplo), a la larga se asumen como costosas con impagados sociales de cuantía (caso de la monoparentalidad o del desarraigo juvenil).

Acabamos nuestro argumento con un apunte sobre el entendimiento de lo que representa el objetivo de aumentar, para el caso de las sociedades aquejadas de individualismo excesivo, la consistencia del orden moral asumido como virtud colectiva. Nos hemos referido ya a la diferencia entre orden moral y orden penal reglamentado por el legislador. Un entorno social comunitario debe regular la conducta social de sus miembros en base a la confianza generada por el sentido de pertenencia en la conciencia moral personal y colectiva, y solo secundariamente en base a la sanción legal. Se entiende el deber - todo derecho implica un debercomo responsabilidad moral y no penal. De ahí que deben de darse las suficientes posibilidades de elección como para que con ciertos límites se permita la libre adscripción moral. Si la pertenencia es obligatoria el deber solo sera provisto por la sanción penal. Por ello muchos comunitaristas son decididos abogados de la causa de la libre adscripcion, lo que traducido al lenguage geopolítico vigente implicaría el reconocimiento a la libre circulación de personas.

Ahora bien, el orden comunitario es decididamente normativo. La distinción que encontramos en Etzioni, Glendon y otros comunitaristas, es en- 
tre valores básicos o seminales y valores periféricos por un lado, y entre orden coercitivo, utilitario y meramente normativo por otro. Los valores compartidos que conforman el orden moral de una comunidad son valores básicos y no periféricos, distinción que cabe hacer también al mismo sujeto colectivo. Los valores básicos conformantes del orden moral son aquellos que en el caso de exceso de autonomía conducen a la consecución del equilibrio social y que Etzioni (1996; 149 y 179) resume en: la defensa colectiva de la familia igualitaria, el entendimiento de la tarea educativa como educación del carácter (virtudes cívicas como tolerancia, solidaridad, respeto y participación), el fomento de la iniciativa local y la asunción de responsabilidades colectivas, la difusión de modelos de comportamiento socialmente saludables, el reparto de soberanía (a la familia y a otras sociedades intermedias religiosas o laicas), y el acuerdo para el fomento de las soluciones consensuadas con el mínimo nivel de representación delegada posible.

Por lo que se refiere a la distinción entre orden coercitivo, utilitario y normativo, hacemos referencia a que el orden comunitarista es de carácter normativo moralmente hablando, enfatizando la distinción con el orden resultante de la imposición penal vigilada policialmente y con el orden incentivado por la análisis económico de la relación coste-beneficio. La confianza del comunitarista para el mantenimiento de su seguridad prima al sentimiento de pertenencia que suponen los valores compartidos sobre la acción estatal pública y sobre el supuesto acuerdo global en maximizar el beneficio.

Acabamos este breve comentario introductorio manifestando nuestra opinión sobre la enorme importancia que tiene en el contexto de los posibles escenarios políticos de futuro el estudio del comunitarismo. La viabilidad de sus premisas y la fundamentación de sus razones, no obstante, tienen que ser baremadas, desde el punto de vista de la formulación de propuestas específicas, en base al análisis del entorno sociocultural en el que supuestamente han de ser aplicadas. Toca pues a los comunitaristas españoles traducir las razones etzinianas en propuestas adecuadas a las circunstancias y peculiaridades locales.

Glosemos ahora, para terminar, los trabajos que componen este monográfico. En «Las propuestas comunitaristas en América y en Europa», Concepción Naval y Alejo Sisón nos brindan un comprensivo y exaustivo análisis sobre las diversas lecturas del comunitarismo y sus orígenes intelectuales e ideológicos. Este ejercicio es necesario para entender, los autores utilizan un enfoque filosófico, de los matices y deferencias entre escuelas. En « Aspectos jurídico-privados del fenómeno comunitario. Diversas situaciones de cotitularidad de bienes y derechos» de Carolina Castillo y en «La Comunidad reconocida: familias, escuelas, y regantes y 
vecinos» de Juan José García de la Cruz y Evaristo Prieto, se analiza primero desde la óptica del derecho y, después, desde la sociología del derecho, las herencias comunitaristas en el derecho de gentes hispano. El análisis de la profesora Castillo se centra en la copropiedad y el de los profesores de la Cruz y Prieto en los derechos colectivos que no implican propiedad. Aspectos ambos que son indispensables para entender la relación de equilibrio entre sociedad e individuo en España. En «La Filosofía Moral y la propuesta de Amitai Etzioni en la Nueva Regla de Oro», José María López de Pedro y Eduardo Lostao analizan desde la óptica propia de la Filosofía Moral y de la Ética la obra de Etzioni. En «Cristianismo y Comunidades: la construcción de la Utopía», Pablo Guerra apunta otra de las ineludibles cuestiones que ha de plantearse el comunitarismo que se exprese en castellano, es éste un factor de indudable importancia. Tampoco se puede dejar de lado el estudio de las relaciones entre «Cooperativa» $\mathrm{y}$ «Comunidad» que aborda la profesora Gómez Cabranes y que constituye un factor diferencial para nuestro país. En «El Kibutz como experiencia comunitarista: realizaciones y limitaciones», Alfonso Carlos Morales también nos presenta otra experiencia de organización social comunitarista premoderna a la que hay que referirse necesariamente. El análisis histórico en la medida en que afecta a las propias herencias culturales, es examinado en «Los Comuneros: un apunte histórico» por Luz María Cruz de Galindo. La profesora Jiménez Ottalengo en «El comunitarismo en los pueblos indígenas de México» nos trae, desde la óptica de la antropología cultural, de nuevo a la consideración la crítica a la idea de progreso que identifica su punto más álgido con la medida en que el individuo se aleja de la comunidad. En «Un comunitarismo radical: el fundamentalismo islámico», por último, el profesor Ruiz Abellán desde la perspectiva de la Ciencia Política, nos introduce en los entresijos de una experiencia comunitaria distorsionada de indudable importancia para el mundo actual.

Como se ve, hemos intentado cubrir con un enfoque genuinamente multidisciplinar y académico todos los aspectos de la cuestión que motiva este trabajo colectivo. Esperamos que el esfuerzo realizado sirva a los propósitos de avance del conocimiento y servicio a la ciencia y a la sociedad que nos ha reunido en torno al tema del comunitarismo.

\section{Bibliografía}

Avineri, Shlomo y De-Shalit, Avner (eds.). Communitarianism and Individualism. Oxford: Oxford University Press.(1992). 


\section{La comunidad: haciendo visible lo invisible}

Bell, Daniel A.. Communitarianism and its Critics. Oxford: Clarendon Press. (1993)

BELLAH, ROBERT ET AL. Habits of the Heart: Individualism and Commitment in american Life. Berkeley: University of California Press. (Traducción española: Alianza).(1985). - The Good Society. Nueva York: Vintage.(1991),

Berger, Peter L. y Neuhaus, Richard J. «Response»in Novak, M (ed) To Empower People: The Role of Mediating Structures in Public Policy. Washington: American Enterprise Institute. (1996).

Bhargava, RaJeev. Individualism in Social Science. Oxford: Oxford University Press. (1992).

Boswell, Jonathan. Community and the Economy: The Theory of Public Cooperation. Londres: Routledge. (1990).

Buber, Martin. ¿Qué es el hombre? México: Fondo de Cultura Económica..(1974).

CALDECOTT, STRATFORD. «Trinity and Society: the Search for a New Way" en The Chesterton Review. Vol. XIX, n. ${ }^{\circ} .4$. (1993)

The Communitarian network. The Responsive communitarian Platform: Rights and Responsabilities, Washington. (1991).

CRITCHFIEld, RichaRd. The Villagers. Nueva York: Anchor. (1994).

CRITTENDEN, JACK. (1992). Beyond Individualism. Oxford: Oxford University Press.

Daly, Markate. Communitarianism: A New Public Ethics. Belmont (CA): Wardsworth. (1994).

d'Entremont, Alban y Pérez Adán, J. (eds.). Desarrollo Socioeconómico y Evolución Demográfica en América Latina. Pamplona: Eunsa. (1999).

Díaz, CARLos. Manifiesto para los humildes. Valenciá: Edim. (1993).

Donati, Pier Paolo. Teoría Relazionale della Società. Milán: Angeli. (1991).

DuRKheim, EMILE. El suicidio. Madrid: Akal.(1976).

Elster, Jon (ed.). The Multiple Self. Cambridge: Cambridge University Press. (1986).

Etzioni, Amitai. The Active Society: A Theory of Societal and Political Processes. Nueva York: Free Press. (1968).

- The Moral Dimension: Towards a New Economics. New York: The Free Press. (1988).

- The Spirit of Community: Rights. Responsabilities and the Communitarian Agenda. New York: Crown. (1993).

— «The Need for a New Paradigm». Responsive Community 5, 1. (1995).

- (ed.) New Communitarian Thinking: Persons. Virtues. Institutions and Communities. Charlottesville: University Press of Virginia.. (1995).

- The New Golden Rule: Community and Morality in a Democratic Society. Nueva York: Basic Books (traducción castellana de Paidos. 1999). (1996).

- The Limits of Privacy. Nueva York: Basic Books. (1999).

- "Communitarian Elements in Select Works of Martin Buber». The Jornal of Value Inquiry. N. ${ }^{\circ} 33$. (1999).

— «The Good Society». The Journal of Political Philosophy. Vol.7, n. ${ }^{\circ} 1$. (1999).

EtzIoni, A. y EtzIon, O. «Face-to-Face and Computer-Mediated Communities, a Comparativer Analysis". The Information Society. 9/99. (1999).

FukUYAma, Francis. El Fin de la Historia y el último hombre. Barcelona: Planeta. (1992).

- Trust: The Social Virtues and the Creation of Prosperity. Nueva York: Free Press. (1995).

Gill, ERIC. A Holy Tradition of Working. Suffolk: Golgonooza. (1983)

Glendon, Mary A.. Rights Talk: The Impoverishment of Political Discourse. Nueva York: Free Press. (1991). 
Gray, John. Post-liberalism: Studies in Political Thought. Nueva York: Routledge. (1993). HERNÁNDEZ ForCADA, R. «Comunitarismo: ¿La tercera vía esperada?» La Cuestión Social, año 3, n. $^{\circ} 3$. (1995).

LeOnard, E., Strasser, H. y Westhues, K. (eds.). In Search of Community: Essays in Memory of Werner Stark (1910-1985). Nueva York: Fordham University Press. (1993).

LIPOVETSKY, Gilles. El crepúsculo del deber. Anagrama. Barcelona. (1994).

MacIntyre, Alasdair. Historia de la Ética. Barcelona: Paidós. (1982).

- Tras la virtud. Barcelona: Crítica. (1987).

- Whose Justice? Which Rationality? London: Duckworth; (Traducción española : Ediciones Internacionales Universitarias). (1988).

— «Después de Tras la virtud» en Atlántida, n 4. (1990).

- Tres versiones rivales de la Ética. Madrid: Rialp. (1992).

- Dependent Rational Animals. Nueva York: Open Court. (1999).

MARTÍNEZ-EcheVARRía y ORTEGA. Miguel Alfonso. «Individualismo metodológico y solidaridad» en VV.AA. Estudios sobre la Encíclica Sollicitudo Rei Socialis. Madrid: Unión Editorial. (1990).

McMylor, Peter. Alasdair MacIntyre: Critic of Modernity. Londres: Routledge. (1994).

Nisbet, Robert. Community and Power. Nueva York: Oxfod University Press. (1962).

- The Social Bond. Nueva York: A. Knopf. (1977).

PÉREz AdÁN, José. heformist Anarchism. Londres: Merlin Books. (1992).

- «Los imperativos ecológicos de un nuevo paradigma». Atlántida, n 16. (1993).

- «El pensamiento ecológico de Juan Pablo II» en AA. VV. Estudios sobre la Encíclica Centessimus Annus. Madrid: AEDOS. (1994).

- «El comunitarismo: una apuesta por la esperanza colectiva». Temas para el Debate, 910. (1995).

- Socioeconomía. Madrid: Trotta. (1997).

- Sociología: concepto y usos. Pamplona: Eunsa. (1997).

- PÉrez AdÁN, J. "Salud social y función familiar» Humana, n. o 3. (1997).

- PÉRez AdÁN, J. «Comunitarismo: hacia una sociología de la virtud». Sociedad y Utopia, n. ${ }^{\circ}$ 10. (1997).

- PÉRez AdÁn, J. «Comunitarismo, moralidad política y la crítica al neoaristotelismo emergente». Sistema, n. ${ }^{\circ}$ 142. (1998).

- Manifiesto Anticonservador; Temas de Sociología Cristiana. Valencia: Carmaiquel. (1998).

- La Salud Social. Madrid: Trotta. (1999).

- «La familia funcional como paradigma comunitario». en García Cabrera, A. y Lucas Marín, A. (eds). Formación y Participación; las organizaciones en el siglo XXI. Las Palmas: SI RC10 de ISA. (1999).

— «Naturaleza: Vernadsky y Boudon contra Aristóteles» en Pardo, M (coord.) Sociología y medio Ambiente: Estado de la Cuestión. Madrid: U. Publica de Navarra-Federación Fernando de los Rios. (1999).

- «A Spanish Viewpoint on Communitarianism». The Responsive Community. Enero, 99. (1999).

- «La Nueva Regla de Oro» Comentario critico. Sistema. 151/99. (1999).

PÉRez AdÁn, J. y ARTAL, M. «Weber y Etzioni, un contencioso sobre los valores» Estudios Filosóficos, n. ${ }^{\circ}$ 127, vol. XLIV. (1995).

PÉrez AdÁn, J., Artal, M. y MARAgUat, E. «Individualismo metodológico y análisis comunitarista. Una presentación del comunitarismo a través de la obra de Amitai Etzioni y Alasdair MacIntyre» Sistema. 124/95. (1995). 
Polany, Karl. The Great Transformation. Boston: Beacon (Traducción española: La Piqueta). (1944).

Putman, Robert. "Bowling Alone, Revisited». The Responsive Community. 5/95. (1995).

SANDel, Michael. Liberalism and the Limits of Justice. Cambridge: Cambridge University Press. (1982).

- (ed.). Liberalism and its Cistics. Oxford: Oxford University Press.

Schluter, Michael y LeE, David. The R Factor. Londres: Hodder \& Stoughton. (1984). (1993).

Schmith, Kenneth L. "Is Liberalism Good Enough?» en Liberalism and the Good. Londres: Routledge. (1990).

SElZnick, Philip. The Moral Commonwealth: Social Theory and the promise of Community. Berkeley: University of California Press. (1992).

TAm, Henry. Communitarianism. Londres: Macmillan. (1998).

TAYLOR, Charles. Sources of the Self. Cambridge (Mas.): Harvard University Press (Traducción española: Paidós). (1989).

TaWney, R. H. The Acquisitive Society. New York: Harcourt. Brace and World. (1920).

Tönnies, Ferdinand Comunidad y Asociación. Barcelona: Península. (1979).

UIMP. Ponencias. Curso: Socioeconomía y Comunitarismo: la búsqueda de paradigmas alternativos. Valencia, 10-12 de Julio. (1995).

VV.AA.. Comunitarismo (4 vols.). Mérida (Ven.): Centro de Estudios Comunitarios. (1984).

Walzer, Michael. «The Communitarian Critique of Liberalism» Political Theory 18, 1. (1990).

— «The Concept of Civil Society» in Walzer, M. (ed) Toward a Global Society. Providence: Berghahn. (1995). 